\title{
Impact of Diversity of Morphological Characteristics and Reynolds number on Local Hemodynamics in Basilar Aneurysms
}

Rafat, Marjan; Dabagh, Mahsa; Heller, Martin; Rabinov, James D.; Stone, Howard A.; Randles, Amanda; Auguste, Debra T.

Published in:

A I Ch E Journal

Link to article, DOI:

10.1002/aic.16091

Publication date:

2018

Document Version

Peer reviewed version

Link back to DTU Orbit

Citation (APA):

Rafat, M., Dabagh, M., Heller, M., Rabinov, J. D., Stone, H. A., Randles, A., \& Auguste, D. T. (2018). Impact of Diversity of Morphological Characteristics and Reynolds number on Local Hemodynamics in Basilar Aneurysms. A I Ch E Journal, 64(7), 2792-2802. https://doi.org/10.1002/aic.16091

\section{General rights}

Copyright and moral rights for the publications made accessible in the public portal are retained by the authors and/or other copyright owners and it is a condition of accessing publications that users recognise and abide by the legal requirements associated with these rights.

- Users may download and print one copy of any publication from the public portal for the purpose of private study or research.

- You may not further distribute the material or use it for any profit-making activity or commercial gain

- You may freely distribute the URL identifying the publication in the public portal 
Impact of Diversity of Morphological Characteristics and Reynolds number on Local Hemodynamics in Basilar Aneurysms

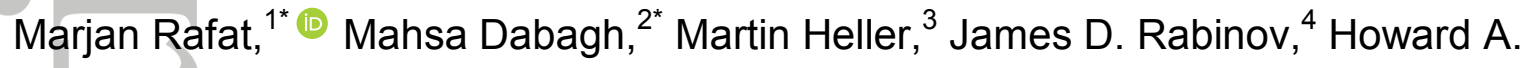
Stone,$^{1 \dagger}$ Amanda Randles, ${ }^{2 \S}$ and Debra T. Auguste ${ }^{1 \S \ddagger}$

${ }^{1}$ School of Engineering and Applied Sciences, Harvard University, Cambridge, MA 02138; ${ }^{2}$ Dept. of Biomedical Engineering, Duke University, Durham, NC 27708; ${ }^{3}$ Dept. of Micro- and Nanotechnology, Technical University of Denmark, DTU Nanotech, DK2800 Kongens Lyngby, Denmark; and ${ }^{4}$ Interventional Neuroradiology, Massachusetts General Hospital, Boston, MA 02114

*These authors contributed equally.

${ }^{\dagger}$ Current Address: Dept. of Mechanical and Aerospace Engineering, Princeton University, Princeton, NJ 08544

${ }^{\ddagger}$ Current Address: Dept. of Chemical Engineering, Northeastern University, Boston, MA

§Corresponding Authors: Email: amanda.randles@duke.edu, d.auguste@northeastern.edu

This article has been accepted for publication and undergone full peer review but has not been through the copyediting, typesetting, pagination and proofreading process which may lead to differences between this version and the Version of Record. Please cite this article as doi: 10.1002/aic.16091 (C) 2018 American Institute of Chemical Engineers (AIChE)

Received: Jun 10, 2017; Revised: Nov 14, 2017; Accepted: J an 08, 2018 


\begin{abstract}
Morphological and hemodynamic parameters have been suggested to affect the rupture of cerebral aneurysms, but detailed mechanisms of rupture are poorly understood. The purpose of our study is to determine criteria for predicting the risk of aneurysm rupture, which is critical for improved patient management. Existing aneurysm hemodynamics studies generally evaluate limited geometries or Reynolds numbers $(\mathrm{Re})$, which are difficult to apply to a wide range of patient-specific cases. We focused on the association between hemodynamic characteristics and morphology. We assessed several two-dimensional (2D) and three-dimensional (3D) idealized and physiological geometries to characterize the hemodynamic landscape between flow patterns. The impact of morphology on velocity and wall shear stress (WSS) profiles were evaluated. We found that slight changes in aneurysm geometry or Re result in significant changes in the hemodynamic and WSS profiles. Our systematic mapping and non-dimensional analysis qualitatively identify hemodynamic conditions that may predispose aneurysms to rupture.
\end{abstract}

Keywords - wall shear stress, Aneurysm geometry, flow patterns, hemodynamics, computational fluid dynamics 


\section{Introduction}

Weak areas in the walls of the vasculature can expand to form blood-filled sacs, or aneurysms. ${ }^{1,2}$ Aneurysms pose a major health risk; approximately 30,000 cerebral aneurysms rupture annually in the US, commonly causing subarachnoid hemorrhage. ${ }^{3}$ Predictions of aneurysm growth and rupture may be achieved by understanding the fluid and solid mechanics of blood flow and vessel structure, respectively. In this study, we use numerical methods to study flow patterns in several aneurysm geometries whose significance has been suggested by clinical studies.

Numerical simulations, computational fluid dynamic (CFD) models, and geometric analyses are among the many approaches taken to study the pathophysiology of aneurysms. Several hypotheses have been made that link geometric factors to aneurysm rupture. For example, studies on the influence of aneurysm morphology (size, aspect ratio, and height-width ratio) on rupture have suggested that the ruptured aneurysms had higher maximum height and aspect ratio. ${ }^{4-7}$ Fan et al. performed CFD analysis on 16 patients with bifurcation mirror aneurysms. ${ }^{5}$ Their analysis showed that aspect ratio was in excellent agreement with their statistical data on ruptured and unruptured cases. Other key parameters including the size and heightwidth ratio are also effective indicators of bifurcation aneurysm rupture. Zhang et al. identified 20 patients with intracranial aneurysm pairs on the same-side of the anterior circulation but with different rupture status. ${ }^{6}$ Their morphological factor analysis suggested that the ruptured aneurysms more often had significantly higher maximum height and aspect ratio. 
However, the rupture of small aneurysms has also been reported. Aneurysm morphology alone is therefore not a reliable factor for prediction of aneurysm rupture risk. ${ }^{4}$ Cebral et al. evaluated the risk of rupture in patient-specific aneurysm geometries using a CFD model based on three-dimensional (3D) angiographs of patients. It was determined that complex flows, small impingement regions, and narrow inflow jets were characteristic of ruptured aneurysms. ${ }^{4,8}$ A correlation between an elliptical shape factor and wall shear stress (WSS) indicated an increased susceptibility to rupture. ${ }^{9}$ We extend this idea by describing the hemodynamic phenomena (i.e. WSS, approximate flow fields) that arise due to changes in aneurysm geometries identified as significant in previous studies. Several idealized $2 \mathrm{D}$ and $3 \mathrm{D}$ aneurysm geometries with different height-width $\left(\mathrm{H}_{\mathrm{A}} / \mathrm{W}_{\mathrm{A}}\right)$ ratios of the aneurysm and neck width-parent vessel width $\left(W_{N} / W_{P}\right)$ ratio were constructed. In addition, two Computed Tomography Angiographic (CTA) images of intracranial aneurysms in different growth stages were applied to reconstrûct realistic $3 \mathrm{D}$ geometries. ${ }^{10}$ Our study provides the context for evaluating physiologically relevant hemodynamic properties on a large scale. We show how the results of $2 \mathrm{D}$ simulations can inform more accurate $3 \mathrm{D}$ simulations, and we point out the overlap between those cases. We applied COMSOL for 2D idealized geometries. However, HARVEY was used for 3D geometries. A key advantage of HARVEY is that it is parallel, which allows the pulsatile blood flow in 3D idealized geometries to be simulated on the order of 5-10 hours and 3D complex geometries to be simulated in 2-3 days. We highlight the use of HARVEY as a way to solve patient-specific cases with improved accuracy. 
We observe flow pattern transition boundaries as a function of geometry and Reynolds number $(\operatorname{Re})$. We also note that recent single-phase and two phase 3D flow studies involving T-junction geometries have highlighted flow transitions including regions of closed streamlines internal to the flow at sufficiently large $\operatorname{Re}$ (typical values are a few hundred). ${ }^{11}$ Particles in the flow can be trapped in these regions. ${ }^{12}$ These hydrodynamic features indicate that flow features important to physiologically relevant geometries remain poorly characterized.

It is clear from this brief survey that many unanswered questions remain for elucidating the link between hemodynamic features, aneurysm geometry, and aneurysm rupture. Though it is generally accepted that hemodynamics is important in understanding the fate of aneurysms, most studies focus on a limited number of geometries and flow rates, which does not allow extension of the conclusions to a wide range of aneurysms. We probe the relationship of aneurysm geometry to flow patterns using non-dimensional terms, which allows for broad application of our data to patientspecific aneurysms. Our findings show that flow characteristics are sensitive to changes in geometry and Re. Because WSS has previously been implicated in aneurysm growth and rupture, we evaluated how the shear stress at the aneurysm wall relates to differences in geometry. ${ }^{13}$ Moreover, we show changes in the hemodynamic factors during the cardiac cycle. Our systematic evaluation of aneurysm hemodynamics may be useful in correlating common features amongst computational investigations that focus on patient-specific data.

\section{Materials and methods}




\section{Aneurysm modeling}

CTA images of the geometry of two different sizes of aneurysm growth stages are shown in Figures 1ai and 1 aii. $^{10}$ In particular, 2D and 3D idealized geometries of a basilar artery aneurysm were constructed based on the CTA images. COMSOL 3.3 and 5.1 Multiphysics FEM software were applied to generate the 2D and 3D geometries, respectively. Mimics software (Materialise, Leuven, Belgium) was used to extract the centerlines of the 3D geometries and Meshlab was applied to convert the files to the compatible form for the CFD code used in the present study.

The 2D and 3D idealized aneurysm geometries were categorized by their heightwidth $\left(\mathrm{H}_{\mathrm{A}} / \mathrm{W}_{\mathrm{A}}\right)$ and neck-parent $\left(\mathrm{W}_{N} / \mathrm{W}_{\mathrm{P}}\right)$ ratios. A schematic of the idealized, $2 \mathrm{D}$ centered aneurysm model is shown in Figure 1b. Physiological widths for the parent (entrance channel) and daughter vessels (branching or bifurcating channels) are $4 \mathrm{~mm}$ and $3 \mathrm{~mm}$, respectively. ${ }^{14}$ We set the lengths of the parent and daughter vessels at 30 and $13 \mathrm{~mm}$, respectively.

In all geometries, the arterial walls are assumed as rigid and the blood behavior through cerebral arteries is considered Newtonian. The flow is characterized by the dimensionless $\operatorname{Re}$ (Eq. 1).

$$
\operatorname{Re}=\frac{\rho W_{P} \bar{u}}{\eta}
$$

where $\rho$ is the density taken as $1060 \mathrm{~kg} / \mathrm{m}^{3}, W_{P}$ is the width of the parent vessel, $\bar{u}$ is the mean velocity, and $\eta$ is the fluid viscosity taken as $3 \mathrm{cP}$. The physiological $\mathrm{Re}$ values of 150 and 300 are used in 3D aneurysms. ${ }^{15}$ In addition, the Womersley number 
(Wo), relating pulsatile to viscous effects, was calculated for pulsatile flows and is defined in Eq. 2:

$$
W o=W p \sqrt{2 \pi \rho / \mathrm{T} \eta}(2),
$$

where $T$ is the period of the waveform calculated based on the heart rate. ${ }^{16}$

Flow patterns were evaluated for aneurysm geometries centered on a bifurcating vessel, offset from a bifurcating vessel, and located on a sidewall vessel. Figures $1 \mathrm{c}$ and $1 \mathrm{~d}$ show representative images for sidewall and offset aneurysms, respectively. Table 1 depicts the heights and widths of all aneurysm geometries used in the $2 \mathrm{D}$ simulations. For each 2D flow map, eleven $\operatorname{Re}(0.5,1,5,10,50,100,150,200,250$, $300,500)$ and four $W_{N} / W_{P}$ ratios $(0.25,0.5,1$, and 1.5$)$ were analyzed. Flow maps were created for $\mathrm{H}_{A} \mathrm{~W}_{\mathrm{A}}$ ratios of $1,1.25,1.5$, and 1.75 (176 simulations in total). The 3D simulations (12 total) spanned two $\operatorname{Re}(150$ and 300$)$, Wo of 5.96 , and six $W_{N} W_{P}$ ratios $\left(0.2,0.25,0.4,0.5,1\right.$, and 1.5). For the CTA cases (2 simulations), the $H_{A} / W_{A}$ is approximately 1 for both cases and $W_{N} W_{P}$ is approximately 1.9 for model 1 (Wo of 5 ) and 1.3 for model 2 (Wo of 7.15).

\section{Computational modeling}

For idealized 2D models, the Navier-Stokes (Eq. 3) and continuity (Eq. 4) equations were solved using the COMSOL 3.3 Multiphysics FEM software:

$$
\begin{gathered}
\rho\left(\frac{\partial \boldsymbol{u}}{\partial t}+(\boldsymbol{u} \cdot \nabla) \boldsymbol{u}\right)=-\nabla p+\eta \nabla^{2} \boldsymbol{u} \\
\nabla \cdot \boldsymbol{u}=0
\end{gathered}
$$

where $p$ is the pressure and $\boldsymbol{u}$ is the velocity vector. The geometries were resolved with a fine mesh with a minimum of 7,400 elements (Figure 1e). Finer meshes were used at the region of the aneurysm and the corners. The convergence was examined through 
the streamlines and WSS profiles by using several mesh sizes. Additionally, WSS profiles were calculated along the aneurysm boundary arc length for varying $H_{A} / W_{A}$ and $\operatorname{Re}(100$ and 400).

We applied HARVEY, ${ }^{17-19}$ a massively parallel computational fluid dynamics code, which implements the lattice Boltzmann method (LBM) for simulations of flow in 3D (realistic and idealized) geometries. LBM is a deterministic, mesoscopic alternative approach to numerically solve the Navier-Stokes equations governing fluid flows. LBM represents a fluid flow by a probability distribution function $f$ of particles, which move at discrete velocities around a fixed Cartesian lattice instead of solving directly for velocity and pressure. Discretizing space and velocity with a fixed Cartesian lattice, LBM models the fluid with a particle distribution function $f_{i}(\vec{x}, t)$, which denotes the probability of finding a particle at time $t$ and lattice point $\vec{x}$ with the discrete velocity $\vec{c}_{i}$. The lattice Boltzmann equation governs the time evolution of $f$ :

$$
f_{i}\left(\vec{x}+\vec{c}_{i} \delta t, t+\delta t\right)-f_{i}(\vec{x}, t)=-\omega\left(f_{i}(\vec{x}, t)-f_{i}^{e q}(\vec{x}, t)\right)
$$

The local equilibrium $f_{i}^{e q}(x, t)$ is the second-order expansion of the local MaxwellianBoltzmann distribution. ${ }^{18}$ HARVEY's implementation of LBM makes use of the standard D3Q19 (the three-dimensional 19 velocity lattice) velocity discretization and the single relaxation time (or BGK) collision kernel $\omega$. We chose the convention D3Q19 previously described due to the isotropy of the lattice. ${ }^{20}$ D3Q19 has proven to be more accurate and stable than the D3Q15 model, and D3Q19 has been shown to be accurate for the flow regimes encountered in this paper. ${ }^{21,22}$ More information about HARVEY may be found in ${ }^{23}$, but a few details regarding the implementation in HARVEY are described here. A no-slip boundary condition is enforced on the rigid vessel walls by the halfway 
bounce-back method while finite difference boundary conditions are used at the inlets and outlets. ${ }^{24}$ To compute the WSS vector $\tau^{\wedge}$, the stress tensor $\sigma_{\alpha \beta}$ is computed from the non-equilibrium distribution $f_{i}^{n e q}(\vec{x}, t)=\left(f_{i}(\vec{x}, t)-f_{i}^{e q}(\vec{x}, t)\right.$. As in Stahl et al., ${ }^{25}$ the outward normal vector $\mathrm{n}^{\wedge}$ is estimated and the WSS vector components computed as:

$$
\tau_{a}=\sigma_{\alpha \beta} n_{\beta}-\left(n_{\beta} \sigma_{\gamma \beta} n_{\gamma}^{\wedge}\right) \hat{n_{\alpha}}(6)
$$

$\tau_{\mathrm{a}}$ is applied to compute transverse WSS using the time independent version of the definition in Peiffer et al. ${ }^{26}$ Further details about the numerical implementation, parallelization, and scaling of HARVEY can be found in 17-19. Simulations were conducted with HARVEY at $100 \mu \mathrm{m}$ resolution (time step of 0.000058 ). We chose to use the parallel HARVEY application because it enabled such high-resolution flows in complex 3D aneurysm geometries on the order of days as opposed to weeks for series applications. Near-optimal scaling efficiency has been demonstrated with HARVEY up to 1.6 million cores. ${ }^{19}$ Parallel efficiency is required to make 3D flow tractable. The data was then extracted for the purpose of WSS quantification. A Matlab code (Matlab R2016a) was applied to calculate the histogram for WSS.

\section{Boundary conditions}

Simulations were performed under steady and pulsatile inflow conditions. For pulsatile flow simulations, a time-dependent physiological velocity waveform was applied at the inlet of $3 \mathrm{D}$ aneurysms, ${ }^{27}$ and pulsatile inflow continued for 5 cardiac cycles $(5 \mathrm{~s})$. For steady flow simulations, a constant inflow rate consistent with the specified Re was applied at the inlet of idealized 2D and 3D models. A zero pressure 
was set at the outlets. The steady inflow continued until the system reached steady state. In all models, the no slip condition was applied at the wall.

\section{Results}

\section{D Intra-arterial flow patterns}

We created 2D flow maps by plotting a range of $W_{N} / W_{P}$ versus $R e$ for multiple $W_{N} W_{P}$ and $H_{A} / W_{A}$ values and qualitatively demarcate the transitions between streamline patterns. Mapping of the distinct flow patterns defined common characteristics that appear as a function of Re and geometry. Six characteristic flow patterns (Figure 2) were found commonly upon altering the aneurysm geometry $\left(H_{A} / W_{A}\right.$, $\left.W_{N} W_{P}\right)$ and $R e$ in centered aneurysms. These patterns were distinguished qualitatively by having symmetrical (Figure 2a) and asymmetrical (Figure 2b) streamline patterns. The patterns showed the formation of eddies (Figures 2ai, 2bi), penetrating bifurcating jets (Figure 2aii, 2bii), and penetrating bifurcating jets with eddies (Figures 2aiii, 2biii).

We graphically depict flow patterns for constant $H_{A} W_{A}$ as a function of $W_{N} / W_{P}$ versus $\mathrm{Re}$ for centered and sidewall aneurysms. Representative images of the aneurysm geometry are placed at the bottom of the centered aneurysm graphs for visualization of $W_{N} / W_{P}$. Flow asymmetry is relative to the midpoint line of the aneurysm centered on the aneurysm neck. The physiologically relevant Re range is located between the dashed lines. For $\mathrm{H}_{A} / \mathrm{W}_{A}=0.5$ in centered aneurysms (Suppl. Figure S1a), we observed a combination of penetrating bifurcating jets and eddies at low $W_{N} / W_{P}$ and $\operatorname{Re}\left(0.2<W_{N} / W_{P}<0.5\right.$ and $\left.\operatorname{Re}<150\right)$. Beyond this regime, only penetrating bifurcating jets were seen. Spherical aneurysms $\left(H_{A} / W_{A}=1\right.$, Figure 3a) resulted in the presence of 
eddies at low $\operatorname{Re}(<100)$ and low $W_{N} / W_{P}(<0.5)$. Penetrating bifurcating jets with eddies were found at intermediate values of $\operatorname{Re}(100<\operatorname{Re}<300)$ for $W_{N} / W_{P}<0.5$ and at low $\operatorname{Re}$ for $W_{N} / W_{P}>0.5$. Asymmetric bifurcating jets dominated at large $\operatorname{Re}$ for $H_{A} W_{A}=1$. Mappings of $\mathrm{H}_{A} / \mathrm{W}_{A}=1.5$ had similar profiles to the results for $\mathrm{H}_{A} / \mathrm{W}_{A}=1$ (Suppl. Figure $\mathrm{S} 1 \mathrm{~b}$ ). When $\mathrm{H}_{\mathrm{A}} \mathrm{W}_{\mathrm{A}}=1.75$ (Suppl. Figure $\mathrm{S} 1 \mathrm{c}$ ), the appearance of asymmetric eddies at low $W_{N} / W_{P}$ was approximately independent of Re. Bifurcating jets with eddies existed beyond $W_{N} / W_{P}>0.5$ but only below physiologically relevant $\operatorname{Re}(100<\operatorname{Re}<400)$. Asymmetric bifurcating jets with eddies were observed for physiological Re over a large range of $W_{N} / W_{P}\left(0.4<W_{N} / W_{P}<1.5\right)$. In addition, all flows were symmetric for the range of Re considered $(0<\operatorname{Re}<500)$ in the $2 \mathrm{D}$ idealized model of the patient angiogram $\left(\mathrm{H}_{A} / \mathrm{W}_{\mathrm{A}}\right.$, $\left.W_{N} W_{P}=1\right)$. We determined that although the angles of the arms were not perpendicular to the parent vessel, the transition from penetrating bifurcating jets with eddies to bifurcating jets at $R e=50$ was similar to the results shown on Figure $3 a$.

Over the entire range of $\mathrm{H}_{A} / \mathrm{W}_{\mathrm{A}}$, asymmetric flows dominated flow patterns in sidewall aneurysms. The characteristic asymmetric flows consisted of penetrating jets with eddies (Figure 2ci), eddies (Figure 2cii), or layered eddies (Figure 2ciii). For $\mathrm{H}_{\mathrm{A}} / \mathrm{W}_{\mathrm{A}}=0.5$ (Suppl. Figure S2a), asymmetric eddies dominated the map except for a small area of penetrating jets with eddies below physiological $\operatorname{Re}(\operatorname{Re}<10)$. Similarly, $\mathrm{H}_{\mathrm{A}} / \mathrm{W}_{\mathrm{A}}=1$ (Figure $3 \mathrm{~b}$ ) predominantly had asymmetric eddies with an area of eddies $\left(W_{N} / W_{P}<0.2\right.$ and $\left.0<\operatorname{Re}<150\right)$ and an area of penetrating jets with eddies at low $R e$ and $W_{N} W_{P}\left(\operatorname{Re}<150\right.$ and $\left.0.22<W_{N} W_{P}<0.5\right)$. The mappings of $H_{A} W_{A}=1.5$ (Suppl. Figure S2b) are similar to graphs for $\mathrm{H}_{A} / \mathrm{W}_{A}=1$; however, asymmetric layered eddies appear in the $H_{A} W_{A}=1.5$ flow map over $0<R e<500$ at all $W_{N} / W_{P}$ ratios. As $H_{A} / W_{A}$ was increased 
to 1.75 (Suppl. Figure S2c), the area on the map of single eddies increased and was independent of $\operatorname{Re}$ for $W_{N} W_{P}<0.5$. An area of penetrating jets with eddies existed for low $\operatorname{Re}(\operatorname{Re}<150)$ and intermediate $W_{N} W_{P}$ values $\left(0.5<W_{N} W_{P}<1\right)$. Asymmetric layered eddies dominated over a large range of $\operatorname{Re}(0<\operatorname{Re}<500)$ at $W_{N} / W_{P}>0.4$.

We also studied flow patterns that arise in aneurysms offset from the inflow (Figure 1d). The characteristic flows in this geometry consisted of eddies, penetrating jets, and penetrating jets with eddies (Suppl. Figure S3a). For $\mathrm{H}_{\mathrm{A}} / \mathrm{W}_{\mathrm{A}}=0.5$ (Suppl. Figure S3b), two types of flows were observed: penetrating jets with eddies at low $W_{N} / W_{P}$ and penetrating jets when $W_{N} / W_{P}>0.5$. When $H_{A} / W_{A}=1$, the flow map was dominated by penetrating jets with eddies except for a region of penetrating jets below physiological $\operatorname{Re}, 0<\operatorname{Re}<60$, and $W_{N} / W_{P}>1$ (Suppl. Figure S3c). The mappings of $H_{A} / W_{A}=1.5$ were similar to graphs for $H_{A} / W_{A}=1.75$ (Suppl. Figure $S 3 d$ ), which displayed penetrating jets with eddies, except for a region of eddies at low $\operatorname{Re}(0<\operatorname{Re}<50)$ and $W_{N} W_{P}\left(0.2<W_{N} W_{P}<1\right)$ (Suppl. Figure S3e).

\section{Hemodynamic Characteristics in 3D models}

Idealized models of aneurysm with steady flow through arteries

We present streamlines in 3D idealized aneurysm models in Figure 4. Figures 4a-h presents the front and side view of streamlines for symmetric aneurysms, and Figures $4 \mathrm{i}-\mathrm{I}$ demonstrates the front view of streamlines for sidewall aneurysms over a range of $H_{A} W_{A}(1-1.75), W_{N} / W_{P}(0.25-1.5)$, and $R e(150-300)$. The streamlines show the formation of eddies in symmetric models (Figures $4 b, d, e, f, h$ ), penetrating bifurcating jets (Figure 4a,b), and penetrating bifurcating jets with eddies in sidewall 
models (Figures 4i-I). Figure 4 shows that penetrating bifurcation jets are observed in smaller $\mathrm{H}_{\mathrm{A}} \mathrm{W}_{\mathrm{A}}$ in symmetric and all sidewall aneurysms where formation of eddies occur in all symmetric models but not in sidewall models.

Figure 5 shows the WSS and velocity distribution in symmetric (Figures 5a-h) and sidewall (Figures 5i-p) aneurysm models. The areas with lower WSS magnitude appear in red. Larger areas of low WSS are observed in models with larger $H_{A} / W_{A}$. Areas of low WSS are smaller for similar geometry and Re in sidewall models compared to the symmetric cases. A similar trend is seen in the velocity distribution. We observe larger areas with low velocity magnitude in aneurysms with larger $H_{A} W_{A}$. Sidewall models show higher magnitude of velocity for the aneurysms with similar $R e$ and $H_{A} / W_{A}$. Idealized models of aneurysm with pulsatile flow through arteries

The impact of flow pulsatility on hemodynamic characteristics was examined by applying the time-dependent physiological waveform at the inlet of the parent artery in 3D idealized geometries. ${ }^{27}$ The streamlines, WSS distribution, and velocity distribution are demonstrated in Suppl. Figure S4a-d. Comparing Suppl. Figure S4 with Figures 4e$\mathrm{f}$ and Figures $5 \mathrm{e}-\mathrm{f}$ (steady flow distribution in similar geometries) reveals that our results with steady flow are in reliable agreement with the pulsatile results. The $\operatorname{Re}$ values applied in 3D models with steady flow are 150 and 300 while a typical physiological $\operatorname{Re}$ in basilar arteries is approximately $280 .^{24}$

Realistic models of aneurysm with pulsatile flow through arteries

We investigated flow patterns in two different patient-specific aneurysm geometries in the basilar artery. Pulsatile flow was applied at the inlet of the parent artery. Figure 6 shows the hemodynamic behavior at systole and diastole for two 
models at two different stages of aneurysm growth. The left panels in Figure 6 illustrate the streamlines of the front and side views for both models. Penetrating bifurcating jets (front view) with eddies (side view) are observed in both models at systole and diastole. Figures $6 \mathrm{~d}, \mathrm{~h}, \mathrm{I}, \mathrm{p}$ demonstrates the WSS over the surface of both cases while Figures $6 \mathrm{c}, \mathrm{g}, \mathrm{k}, \mathrm{o}$ shows the velocity distribution over the surface of both realistic models. The blebs observed in model 2 experience low WSS even at systole. Model 1 also has areas (small blebs) with low WSS, where model 1 represents a larger-sized aneurysm. The areas with low WSS occupy a larger part of the aneurysm in both models, and this is better visualized at systole (Figures $6 \mathrm{~d}, \mathrm{I}$ ). A similar trend is observed for the velocity distribution (Figures 6c, k). Areas with low WSS magnitude and low velocity magnitudes vary between systole and diastole. Low WSS has been suggested as a reliable indicator of aneurysm rupture. ${ }^{5}$ Zhang $Y$ et al. also reported that larger areas of low WSS might indicate a higher risk for aneurysm rupture. ${ }^{6}$

\section{Wall shear stress analysis}

2D Models

The 2D WSS profile and corresponding streamlines are shown in Figure 7ai for $H_{A} / W_{A}=1.75, R e=400$, and $W_{N} / W_{P}=1$ in a centered aneurysm model. It is convenient to present these results by reporting the arc length ratio, by which we denote the fraction of the arc length that experienced low shear stress $\left(<0.01 \mathrm{~N} / \mathrm{m}^{2}\right)$. The results utilize an arc length which is non-dimensionalized by the parent vessel width. As $H_{A} / W_{A}$ increased, the fraction of the aneurysm arc length that experienced low WSS $(<0.01$ $\mathrm{N} / \mathrm{m}^{2}$ ) increased (Figure 7aii). The magnitude of the WSS increased with $R e$ and $H_{A} W_{A}$ 
despite affecting a smaller area. The maximum WSS reached approximately $2 \mathrm{~N} / \mathrm{m}^{2}$ and $23 \mathrm{~N} / \mathrm{m}^{2}$ at $R e=100$ and 400 , respectively, for $H_{A} / W_{A}=1.75$. For constant geometry, the arc length ratio with low WSS decreased with increasing Re (Figure 7aii).

For offset aneurysms, the WSS profiles were asymmetric. Figure $7 \mathrm{bi}$ illustrates the WSS profile and streamlines for $H_{A} / W_{A}=1.75, R e=400$, and $W_{N} / W_{P}=1$. The WSS was high where the flow impinged upon the aneurysm and decreased significantly along the wall. The maximum WSS for offset aneurysms reached approximately $4.5 \mathrm{~N} / \mathrm{m}^{2}$ and $40 \mathrm{~N} / \mathrm{m}^{2}$ at $R e=100$ and 400 , respectively, for $H_{A} N_{A}=1.75$, but the increase in low WSS along the aneurysm wall was still apparent as $\mathrm{H}_{\mathrm{A}} \mathrm{W}_{\mathrm{A}}$ increased (Figure $7 \mathrm{bii}$ ). We did not observe a significant difference in the arc length ratio of low WSS at $\operatorname{Re}=100$ and 400 for $H_{A} W_{A}=0.5$, 1, or 1.75. For $H_{A} / W_{A}=0.5$, the WSS remained above $0.01 \mathrm{~N} / \mathrm{m}^{2}$. Similarly, sidewall aneurysm WSS profiles were asymmetric but had magnitudes greater than $0.01 \mathrm{~N} / \mathrm{m}^{2}$ for the conditions tested ( $R e=100,400$ and $H_{A} / W_{A}=0.5,1$, and 1.75). The maximum WSS for sidewall aneurysms reached approximately $9 \mathrm{~N} / \mathrm{m}^{2}$ and $40 \mathrm{~N} / \mathrm{m}^{2}$ at $\mathrm{Re}=100$ and 400 , respectively, for $\mathrm{H}_{\mathrm{A}} \mathrm{W}_{\mathrm{A}}=1.75$.

3D idealized and realistic models

The magnitude of WSS of aneurysm models with different morphological parameters and Re and Wo were quantified. In-house MATLAB codes (Matlab R2016a, The MathWorks Inc., Natick, MA) were used to calculate the histograms of WSS for all aneurysm models. Figures 8a-c demonstrate the histograms for 3D idealized and realistic models. Figure $8 a$ shows the quantification of WSS magnitude for four symmetric aneurysms, and Figure $8 \mathrm{~b}$ presents the WSS quantification for four sidewall aneurysms. Figure 8c demonstrates the WSS quantification for two realistic aneurysm 
models at systole and diastole. The magnitude of WSS is significantly affected by the size of aneurysm, aneurysm neck diameter, Re, and Wo. Areas of low WSS are larger for symmetric aneurysms than sidewall ones. As the $\mathrm{H}_{A} / W_{A}$ increases, areas of low WSS also increase in symmetric and sidewall cases. The distribution of areas with low WSS is uniform in realistic models and have the same values at systole and diastole. Model 2 has larger areas of low WSS.

\section{Discussion}

Previous studies that investigated aneurysm rupture have implicated aneurysm geometry and the perianeurysmal environment in combination with the hemodynamic environment as the determinants for aneurysm rupture. This study has systematically examined the hemodynamic and WSS profiles of clinically relevant and idealized aneurysm geometries for a range of physiological Re to establish accurate criteria to predict the risk of aneurysm rupture. We have analyzed how changes in geometry, Re, and Wo alter hemodynamic profiles in idealized and physiological aneurysm geometries and have identified transition boundaries where the flow patterns change categorically. Knowledge about the basic flow characterizations may facilitate our understanding of how the hemodynamic landscape and WSS affect complex biological processes. ${ }^{13,16,28,29}$ Aneurysm growth and rupture most likely result from a combination of physical and biological phenomena. For example, changes in flow and WSS have been shown to regulate endothelial gene expression. ${ }^{30,31}$ Our systematic mapping and non-dimensional analysis of flow patterns as a function of $\mathrm{Re}$, geometric shape factors, and aneurysm location identify qualitatively the hemodynamic conditions that may 
predispose aneurysms to rupture. Qualitative identification of such hemodynamic shifts may be used to set the framework for understanding flow regimes that can inform the basis for more accurate and quantitative patient-specific analyses as we have shown.

Although we do not expect an exact match between idealized 2D and 3D simulations, we have demonstrated that there are similarities between $2 \mathrm{D}$ and $3 \mathrm{D}$ simulations (Figures 3, 4). For example, symmetric aneurysms show significant overlap between the two cases: we observe asymmetric bifurcating jets with eddies (Figures $4 a$, e) and asymmetric bifurcating jets (Figures 4c, g) across geometric parameters and Re. However, Figure $4 \mathrm{~h}$ reveals eddies that were not seen in $2 \mathrm{D}$ simulations. The discrepancy in streamlines highlights the impact of aneurysm morphology and magnitude of $\operatorname{Re}$ on hemodynamic characteristics. Sidewall aneurysm flow patterns in $3 \mathrm{D}$ also overlap with 2D simulations: 2D flow maps predict asymmetric eddies (Figure 4i) and asymmetric layered eddies (Figures $4 \mathrm{j}, \mathrm{I})$. Although asymmetric layered eddies are predicted in 2D simulations, we see only eddies in sidewall aneurysms with $H_{A} / W_{A}=1.75, W_{N} W_{P}=1.5, R e=300$ (Figure 4k). Despite this difference, we have shown that the $2 \mathrm{D}$ and $3 \mathrm{D}$ simulations agree to a great extent. In addition, flow patterns similar to those in our analyses have been reported in the literature. ${ }^{32}$ For example, Utter and Rossmann show penetrating bifurcating jets with eddies in their analysis of centered aneurysms with $H_{A} / W_{A}=1$ and $W_{N} / W_{P}=1$, while Hoi et al. found asymmetric eddies in their evaluation of the hemodynamics in sidewall aneurysms with $\mathrm{H}_{A} \mathrm{~W}_{\mathrm{A}}=1, \mathrm{~W}_{\mathrm{N}} / \mathrm{W}_{\mathrm{P}}=2.5$, and $\operatorname{Re}=136 .{ }^{9,33}$ Thus, we find qualitative agreement between our analysis and other reports. 
We began with $2 \mathrm{D}$ simulations to determine the feasibility of our flow map analysis. While these have limited clinical applicability, we used these initial results to build more relevant $3 \mathrm{D}$ models. We transitioned from using COMSOL for FEM to HARVEY to implement the LBM due to the increase in computing power and the improvement in accuracy in 3D complex geometries, particularly patient-specific cases. ${ }^{18}$ FEM and LBM approaches have been compared in previous studies. ${ }^{34-36}$ When simulating systolic blood flow in the abdominal aorta and mesenteric artery using both FEM and LBM, it was found that the LBM is as accurate as FEM for solving complex blood flows. ${ }^{35}$ In addition, a study assessed both methods when simulating flow in 2D and 3D simplified intracranial aneurysm models, and flow and vorticity were in good agreement between the two methods. ${ }^{36}$ LBM was found to have improved cost per time step, code implementation, and parallelization. The wall shear stress in the human abdominal aorta has also been computed by the LBM, a standard finite volume solver, and experimental data available in the literature, and the three methods were comparable. ${ }^{37}$ Chapman-Enskog analysis furthermore showed that LBM reproduces the incompressible Navier-Stokes equations. ${ }^{38,39}$ Therefore, using the LBM is appropriate for high resolution 3D simulations.

We have identified common flow patterns and transition boundaries for a broad range of aneurysms. Several aneurysm geometries have flow patterns that are independent of changes in Re. Consequently, changes in flow velocity or viscosity do not qualitatively affect hemodynamics. For example, Perktold et al. found that altering Re from 150 to 250 does not significantly affect the flow pattern of penetrating bifurcating jets for offset aneurysms with $H_{A} / W_{A}=1$ and $W_{N} W_{P}=0.825 .{ }^{14}$ These flow 
patterns correspond to our flow map in Suppl. Figure S3c. However, in some instances, small changes in Re or geometric shape factors can alter the flow profile. For example, Hoi et al. showed that the impingement area increased significantly as the curvature of the parent artery increased for sidewall aneurysms with $\mathrm{H}_{\mathrm{A}} \mathrm{W}_{\mathrm{A}}=1, \mathrm{~W}_{\mathrm{N}} / \mathrm{W}_{\mathrm{P}}=2.5$ and $\mathrm{Re}=136$, causing the flow patterns to change from eddies to penetrating jets with eddies. ${ }^{33}$ Our mapping of the hemodynamic landscape identifies relationships between aneurysm geometry and flow characteristics.

Aneurysm location, geometry, and $\mathrm{Re}$ dictate the presence of transition boundaries between distinct flow profiles. Figure 5 and Suppl. Figure S4 show that distributions of WSS and velocity are significantly associated with aneurysm morphology, location, Wo, and Re. Moreover, our results show that the size of low WSS areas are directly linked to aneurysm geometry. We observe larger areas of low WSS in aneurysms with larger $\mathrm{H}_{\mathrm{A}} \mathrm{W}_{\mathrm{A}}$, shown in Figure 7 for $2 \mathrm{D}$ centered aneurysms and in Figures $8 a-b$ for 3D models. The same trend was reported by Fan et al., where it was concluded that higher aspect ratio and low WSS areas are reliable indicators of aneurysm rupture. ${ }^{5}$ Zhang et al. also reported that larger size and more areas of low WSS might indicate a higher risk for aneurysm rupture. ${ }^{6}$ The comparison of Suppl. Figure $\$ 4$ and Figure 5 reveals that the assumption of steady flow is appropriate for idealized $2 \mathrm{D}$ and $3 \mathrm{D}$ geometries as the results did not change at different cardiac time points.

The WSS and velocity distribution for realistic models at systole and diastole are shown in Figure 6. Irregularities in the geometry of models 1 and 2 lead to varying hemodynamic characteristics and different Wo as compared to the idealized models. ${ }^{16}$ 
The blebs and sharp areas of the aneurysms experience lower WSS and velocity magnitudes. Irregular aneurysm shape has also been reported as an indicator for a higher rupture risk along with high aspect ratio and greater areas of low WSS area.,6 Asgharzadeh and Borazjani reported that high values of Wo affect the hemodynamics of aneurysms and may be used to predict the probability of aneurysm rupture. ${ }^{16}$ Our results are in agreement with those findings as our model $2(\mathrm{Wo}=7.15)$, where we see greater areas of low WSS, has a higher Wo than model 1 (Wo=5).

Several studies disagree about how the magnitude of WSS relates to aneurysm growth and rupture. In a computational study that modeled patient aneurysms, it was found that the areas of highest WSS were near the neck of the aneurysm while the shear stress significantly decreased in the aneurysm dome area. ${ }^{29}$ They concluded that low WSS along the aneurysm wall may facilitate aneurysm growth and rupture while high WSS contributes to the initial development of an aneurysm. In addition, low WSS along the aneurysm wall has been found to correlate to aneurysm growth and rupture in two independent, patient-specific computational studies. ${ }^{40,41}$ In contrast, some studies have linked high WSS to aneurysm progression. ${ }^{33,42,43}$ Our analysis shows that the appearance of eddies, which correlates to an increase in $\mathrm{H}_{\mathrm{A}} / \mathrm{W}_{\mathrm{A}}$, is accompanied by an increase in areas of low WSS along the aneurysm boundary (Figures 3,7 ). This result could be associated with the finding that increases in $\mathrm{H}_{\mathrm{A}} \mathrm{W}_{\mathrm{A}}$ are associated with increased rupture. ${ }^{44}$ However, it is also possible that changes in the magnitude of WSS along the aneurysm wall contribute to growth and rupture. Nonetheless, WSS appears to play a critical role in predicting aneurysm wall remodeling and rupture. 
We have categorized flow patterns based on geometry and flow characteristics. Our assumptions allowed us to perform simulations that identify macroscopic flow features and transition boundaries that correlate with patient-specific aneurysms. Our focus in this study is on the systematic organization of hemodynamic patterns into "flow maps" that categorize qualitatively distinct flow features and transition boundaries. In this approach, we believe the assumptions made are reasonable to describe the qualitative features of flow. Vessel elasticity has not been shown to significantly alter flow patterns or the average velocity within aneurysm geometries. ${ }^{13,14,28}$ It is not our position that these simulations mimic clinical aneurysms exactly but that analysis of aneurysm shape factors and flow conditions in a systematic fashion that can be used to recognize common hemodynamic patterns and transition boundaries. Our nondimensional analysis may be broadly applied to a wide range of patient-specific aneurysms. Our findings indicate an increase in eddies for bifurcating vessels and layered eddies for sidewall vessels for increasing $H_{A} / W_{A}$ and $W_{N} / W_{P}$. We demonstrate that small changes in aneurysm geometry or Re can result in distinct changes in the hemodynamic and WSS profiles. This may correlate with changes in cellular function that affect vascular biology and structure leading to aneurysm growth and rupture.

\section{Acknowledgments}

Martin Heller was supported by the Danish Research Council for Technology and Production Sciences grant no. 26-04-0074. The authors would like to thank Dr. Derek Vigil for his preliminary analysis of aneurysm fluid flow and shear stress and Jesse Prakken, Niu Miyun, and Suniti Mohan for their help in preparation of 3D results. 


\section{Literature Cited}

1. Lasheras JC. The biomechanics of arterial aneurysms. Annu Rev Fluid Mech. 2007;39:293-319.

2. Mantha AR, Benndorf G, Hernandez A, Metcalfe RW. Stability of pulsatile blood flow at the ostium of cerebral aneurysms. J Biomech. 2009;42(8):1081-1087.

3. Zacharia BE, Hickman ZL, Grobelny BT, DeRosa P, Kotchetkov I, Ducruet AF, Connolly ES, Jr. Epidemiology of aneurysmal subarachnoid hemorrhage. Neurosurg Clin N Am. 2010;21(2):221-233.

4. Cebral JR, Mut F, Weir J, Putman CM. Association of hemodynamic characteristics and cerebral aneurysm rupture. $A m \quad J$ Neuroradiol. 2011;32(2):264-270.

5. Fan J, Wang Y, Liu J, Jing L, Wang C, Li C, Yang X, Zhang Y. Morphologicalhemodynamic characteristics of intracranial bifurcation mirror aneurysms. World Neurosurg. 2015;84(1):114-120.

6. Zhang Y, Yang X, Wang Y, Liu J, Li C, Jing L, Wang S, Li H. Influence of morphology and hemodynamic factors on rupture of multiple intracranial aneurysms: matched-pairs of ruptured-unruptured aneurysms located unilaterally on the anterior circulation. BMC Neurol. 2014;14:253.

7. Ujiie H, Tachibana H, Hiramatsu O, Hazel AL, Matsumoto T, Ogasawara Y, Nakajima H, Hori T, Takakura K, Kajiya F. Effects of size and shape (aspect ratio) on the hemodynamics of saccular aneurysms: a possible index for surgical treatment of intracranial aneurysms. Neurosurg. 1999;45:119-129. 
8. Cebral JR, Castro MA, Burgess JE, Pergolizzi RS, Sheridan MJ, Putman CM. Characterization of cerebral aneurysms for assessing risk of rupture by using patient-specific computational hemodynamics models. Am J Neuroradiol. 2005;26(10):2550-2559.

9. Utter B, Rossmann JS. Numerical simulation of saccular aneurysm hemodynamics: influence of morphology on rupture risk. $J$ Biomech. 2007; 40(12):2716-2722.

10. Emory U. AneuriskWeb project. 2012.

11. Ault JT, Fani A, Chen KK, Shin S, Gallaire F, Stone HA. Vortex-breakdowninduced particle capture in branching junctions. Phys Rev Lett. 2016;117(8):084501.

12. Vigolo D, Radl S, Stone HA. Unexpected trapping of particles at a $\mathrm{T}$ junction. Proc Natl Acad Sci. 2014;111(13):4770-4775.

13. Meng H, Wang Z, Hoi Y, Gao L, Metaxa E, Swartz DD, Kolega J. Complex hemodynamics at the apex of an arterial bifurcation induces vascular remodeling resembling cerebral aneurysm initiation. Stroke. 2007;38(6):1924-1931.

14. Perktold K, Kenner T, Hilbert D, Spork B, Florian H. Numerical blood flow analysis: arterial bifurcation with a saccular aneurysm. Basic Res Cardiol. 1988;83(1):24-31.

15. DeGroff CG, Thornburg BL, Pentecost JO, Thornburg KL, Gharib M, Sahn DJ, Baptista A. Flow in the early embryonic human heart: a numerical study. Pediatr Cardiol. 2003;24(4):375-380. 
16. Asgharzadeh H, Borazjani I. Effects of Reynolds and Womersley numbers on the hemodynamics of intracranial aneurysms. Comput Math Methods Med. 2016;2016:7412926.

17. Randles AP, Kale V, Hammond J, Gropp W, Efthimios K. Performance analysis of the lattice Boltzmann model beyond Navier-Stokes. 2013 IEEE 27th International Symposium on Parallel \& Distributed Processing. 2013;1063-1074.

18. Randles A, Draeger EW, Bailey PE. Massively parallel models of the human circulatory system. J Comp Sci. 2015;9:70-75.

19. Randles A, Draeger EW, Oppelstrup T, Krauss L, Gunnels JA. Massively parallel models of the human circulatory system. Proceedings of the International Conference for High Performance Computing, Networking, Storage and Analysis. 2015;1-11.

20. Qian YH, Humieres D, Lallemand P. Lattice BGK models for Navier-Stokes equation. Europhys Lett. 1992;17(6):479.

21. Huidan Y, Girimaji S, Luo L. DNS and LES of decaying isotropic turbulence with and without frame rotation using lattice Boltzmann method. J Comput Phys. 2005;209(2):599-616.

22. Dinan W, Bernsdorf J. Lattice Boltzmann simulation of steady non-Newtonian blood flow in a 3D generic stenosis case. Comput Math Appl. 2009;58(5):10301034.

23. Succi S. The lattice Boltzmann equation: for fluid dynamics and beyond. New York: Oxford University Press, Inc., 2001. 
24. Latt J, Chopard B, Malaspinas O, Deville M, Michler A. Straight velocity boundaries in the lattice Boltzmann method. Phys Rev E. 2008;77(5 Pt 2):056703.

25. Stahl B, Chopard B, Latt J. Measurements of wall shear stress with the lattice boltzmann method and staircase approximation of boundaries. Comp Fluids. 2010;39:1625-1633.

26. Peiffer V, Sherwin SJ, Weinberg PD. Computation in the rabbit aorta of a new metric - the transverse wall shear stress - to quantify the multidirectional character of disturbed blood flow. J Biomech. 2013;46(15):2651-2658.

27. Enzmann DR, Ross MR, Marks MP, Pelc NJ. Blood flow in major cerebral arteries measured by phase-contrast cine MR. Am $J$ Neuroradiol. 1994;15(1):123-129.

28. Rayz VL, Boussel L, Lawton MT, Acevedo-Bolton G, Ge L, Young WL, Higashida RT, Saloner D. Numerical modeling of the flow in intracranial aneurysms: prediction of regions prone to thrombus formation. Ann Biomed Eng. 2008;36(11):1793-1804.

29. Shojima M, Oshima M, Takagi K, Torii R, Hayakawa M, Katada K, Morita A, Kirino T. Magnitude and role of wall shear stress on cerebral aneurysm: computational fluid dynamic study of 20 middle cerebral artery aneurysms. Stroke. 2004;35(11):2500-2505.

30. Chen BP, Li YS, Zhao Y, Chen KD, Li S, Lao J, Yuan S, Shyy JY, Chien S. DNA microarray analysis of gene expression in endothelial cells in response to 24-h shear stress. Physiol Genomics. 2001;7(1):55-63. 
31. Chien S. Effects of disturbed flow on endothelial cells. Ann Biomed Eng. 2008;36(4):554-562.

32. Paal G, Ugron A, Szikora I, Bojtar I. Flow in simplifed and real models of intracranial aneurysms. Int J Heat Fluid FI. 2007;28(653-664.

33. Hoi Y, Meng H, Woodward SH, Bendok BR, Hanel RA, Guterman LR, Hopkins LN. Effects of arterial geometry on aneurysm growth: three-dimensional computational fluid dynamics study. J Neurosurg. 2004;101(4):676-681.

34. Kwon YW, Hosoglu S. Application of lattice Boltzmann method, finite element method, and cellular automata and their coupling to wave propagation problems. Comput Struct. 2008;86(7-8):663-670.

35. Axner L, Hoekstra AG, Jeays A, Lawford P, Hose R, Sloot PM. Simulations of time harmonic blood flow in the Mesenteric artery: comparing finite element and lattice Boltzmann methods. Biomed Eng Online. 2009;8:23.

36. Weichert F, Walczak L, Fisseler D, Opfermann T, Razzaq M, Munster R, Turek S, Grunwald I, Roth C, Veith C, Wagner M. Simulation of intra-aneurysmal blood flow by different numerical methods. Comput Math Methods Med. 2013;2013:527654.

37. Luo LS. Theory of the lattice boltzmann method: lattice boltzmann models for nonideal gases. Phys Rev E. 2000;62(4 Pt A):4982-4996.

38. He X, Luo LS. Lattice Boltzmann model for the incompressible Navier-Stokes equation. J Statis Phys. 1997;88(3):927-944.

39. Matyka M, Koza Z, Miroslaw L. Wall orientation and shear stress in the lattice Boltzmann model. Comput Fluids. 2013;73:115-123. 
40. Boussel L, Rayz V, McCulloch C, Martin A, Acevedo-Bolton G, Lawton M, Higashida R, Smith WS, Young WL, Saloner D. Aneurysm growth occurs at region of low wall shear stress: patient-specific correlation of hemodynamics and growth in a longitudinal study. Stroke. 2008;39(11):2997-3002.

41. Jou LD, Lee DH, Morsi H, Mawad ME. Wall shear stress on ruptured and unruptured intracranial aneurysms at the internal carotid artery. $A m \mathrm{~J}$ Neuroradiol. 2008;29(9):1761-1767.

42. Cebral JR, Hendrickson S, Putman CM. Hemodynamics in a lethal basilar artery aneurysm just before its rupture. Am J Neuroradiol. 2009;30(1):95-98.

43. Hassan T, Timofeev EV, Saito T, Shimizu H, Ezura M, Matsumoto Y, Takayama K, Tominaga T, Takahashi A. A proposed parent vessel geometry-based categorization of saccular intracranial aneurysms: computational flow dynamics analysis of the risk factors for lesion rupture. J Neurosurg. 2005;103(4):662-680.

44. Hoh BL, Sistrom CL, Firment CS, Fautheree GL, Velat GJ, Whiting JH, ReaveyCantwell JF, Lewis SB. Bottleneck factor and height-width ratio: association with ruptured aneurysms in patients with multiple cerebral aneurysms. Neurosurg. 2007;61(4):716-723. 


\section{Tables}
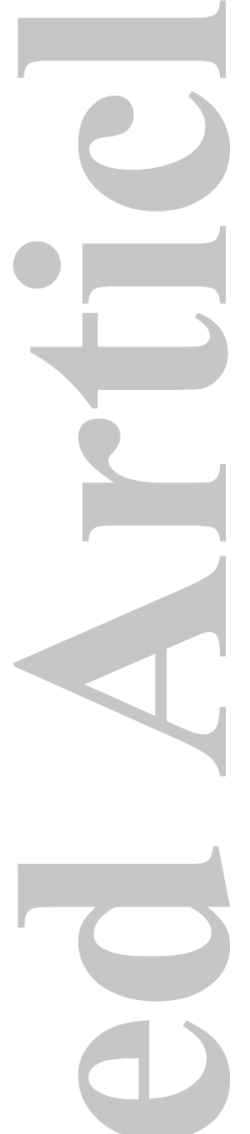

\begin{tabular}{c|c|c}
$\mathrm{H}_{\mathrm{A}} \mathrm{W}_{\mathrm{A}}$ & $\begin{array}{c}\text { Height } \\
(\mathrm{mm})\end{array}$ & $\begin{array}{c}\text { Width } \\
(\mathrm{mm})\end{array}$ \\
\hline & 0.5 & 1 \\
0.5 & 1 & 2 \\
& 2 & 4 \\
& 3 & 6 \\
\hline & 1 & 1 \\
1 & 2 & 2 \\
& 4 & 4 \\
& 6 & 6 \\
\hline & 1.25 & 1 \\
1.25 & 2.5 & 2 \\
& 5 & 4 \\
& 7.5 & 6 \\
\hline & 1.5 & 1 \\
1.5 & 3 & 2 \\
& 6 & 4 \\
& 9 & 6 \\
\hline & 1.75 & 1 \\
& 3.5 & 2 \\
& 7 & 4 \\
& 10.5 & 6
\end{tabular}

Table 1. Aneurysm Dimensions used in Simulations

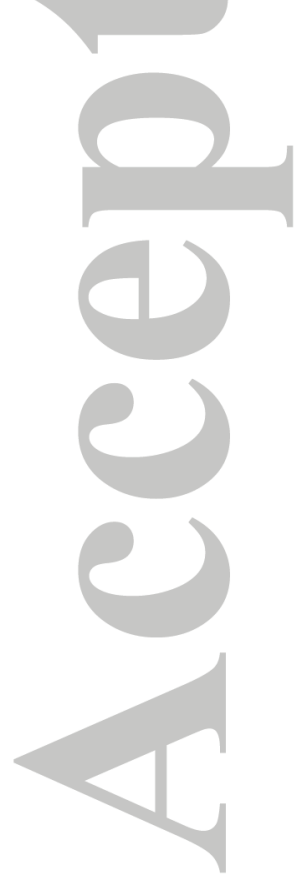

\section{AIChE 28 Journal}

This article is protected by copyright. All rights reserved. 


\section{Figure Legends}

FIGURE 1. Definition of parameters used in simulations. (a) CTA images of patient aneurysms. i) Model 1. ii) Model 2. (b) 2D centered aneurysm model. The height $\left(\mathrm{H}_{\mathrm{A}}\right)$ and width $\left(\mathrm{W}_{\mathrm{A}}\right)$ of the aneurysm are indicated by solid vertical and horizontal lines, respectively. The width of the neck $\left(W_{N}\right)$ and parent vessel $\left(W_{P}\right)$ are shown, respectively, by a dashed horizontal line and arrows. (c) Representative offset aneurysm. (d) Representative sidewall aneurysm. (e) Typical mesh used to resolve the aneurysm geometries.

FIGURE 2. Representative streamline patterns. (a) 2D Symmetric flow streamlines. i) Eddies $\left(\operatorname{Re}=0.5, \quad H_{A} / W_{A}=1, \quad W_{N} W_{P}=0.25\right)$. ii) Penetrating bifurcating jets (Re=500, $\left.\mathrm{H}_{A} \mathrm{~W}_{\mathrm{A}}=0.5, \mathrm{~W}_{\mathrm{N}} \mathrm{W}_{\mathrm{P}}=0.5\right)$. iii) Penetrating bifurcating jets with eddies $\left(\operatorname{Re}=200, \quad H_{A} W_{A}=1.5, \quad W_{N} W_{P}=0.4\right)$. (b) Asymmetric flow streamlines. i) Asymmetric eddies $\left(R e=1, H_{A} / W_{A}=1.75, W_{N} / W_{P}=0.2\right)$. ii) Penetrating bifurcating jets $\left(R e=500, H_{A} / W_{A}=1.5, W_{N} / W_{P}=1\right)$. iii) Penetrating bifurcating jets with eddies $\left(\operatorname{Re}=150, H_{A} / W_{A}=1.75, W_{N} W_{P}=1.5\right)$. (c) Characteristic asymmetric flows in sidewall aneurysms: i) Penetrating jets with eddies $\left(\operatorname{Re}=5, H_{A} / W_{A}=1\right.$, $\left.W_{N} W_{P}=1.5\right)$. ii) Eddies $\left(R e=300, H_{A} / W_{A}=1, W_{N} W_{P}=1.5\right)$. iii) Layered eddies $\left(R e=500, H_{A} / W_{A}=1.5, W_{N} / W_{P}=0.5\right)$.

FIGURE 3. Qualitative mapping of 2D flow patterns. Flow pattern maps for (a) center terminated and (b) sidewall aneurysms for $\mathrm{H}_{\mathrm{A}} / \mathrm{W}_{\mathrm{A}}=1$ in terms of various Reynolds numbers $(R e)$ and neck to parent width $\left(W_{N} / W_{P}\right)$ ratios. Dashed lines indicate physiological Re. Arrows specify flow direction. 
FIGURE 4. Streamlines developed in 3D idealized aneurysm models. (a) Front and (b) side view of a symmetric aneurysm $\left(H_{A} / W_{A}=1, W_{N} / W_{P}=0.25, R e=300\right)$. (c) Front and (d) side view of a symmetric aneurysm $\left(\mathrm{H}_{A} / \mathrm{W}_{\mathrm{A}}=1.5, \mathrm{~W}_{N} / \mathrm{W}_{\mathrm{P}}=1\right.$, $R e=300)$. (e) Front and (f) side view of a symmetric aneurysm $\left(H_{A} / W_{A}=1.75\right.$, $\left.W_{N} W_{P}=1.5, R e=300\right)$. (g) Front and (h) side view of a symmetric aneurysm $\left(H_{A} / W_{A}=1.5, W_{N} W_{P}=1, R e=150\right.$. Front view of a sidewall aneurysms: (i) $H_{A} / W_{A}$ =1, $W_{N} / W_{P}=0.25, R e=300$. (j) $H_{A} / W_{A}=1.5, W_{N} W_{P}=1, R e=300$. (k) $H_{A} / W_{A}=1.75$, $W_{N} / W_{P}=1.5, R e=300$. (I) $H_{A} / W_{A}=1.5, W_{N} / W_{P}=1, R e=150$. A color code is shown indicating the magnitude of velocity in units $\mathrm{m} / \mathrm{s}$.

FIGURE 5. WSS and velocity distribution over the aneurysm surface in 3D idealized models. Symmetric aneurysms: (a, b) $R e=300, H_{A} / W_{A}=1$, $W_{N} W_{P}=0.25$. (c, d) $R e=300, H_{A} / W_{A}=1.5, W_{N} / W_{P}=1$. (e, f) $R e=300, H_{A} / W_{A}=1.75$, $W_{N} W_{P}=1.5 .(\mathbf{g}, \mathbf{h}) \operatorname{Re}=150, H_{A} / W_{A}=1.5, W_{N} / W_{P}=1$. Sidewall aneurysms: (i, j) $R e=300, H_{A} / W_{A}=1, W_{N} / W_{P}=0.25$. (k, l) $R e=300, H_{A} / W_{A}=1.5, W_{N} / W_{P}=1 .(m, n)$ $R e=300, H_{A} / W_{A}=1.75, W_{N} / W_{P}=1.5$. (o, p) $R e=150, H_{A} W_{A}=1.5, W_{N} / W_{P}=1$, $\mathrm{Re}=150$. A color code is shown indicating the magnitude of WSS in units Pa and velocity in units $\mathrm{m} / \mathrm{s}$.

FIGURE 6. Hemodynamic characteristics of 3D physiological aneurysms at systole and diastole. (a) Front and (b) side view of streamlines within the aneurysm at systole, model 1. (c) WSS and (d) velocity distribution over the aneurysm surface at systole, model 1. (e) Front and (f) side view of streamlines within the aneurysm at diastole, model 1. (g) WSS and (h) velocity distribution 
over the aneurysm surface at diastole, model 1. (i) Front and (j) side view of streamline inside the aneurysm at systole, model 2. (k) WSS and (I) velocity distribution over the surface of aneurysm at systole time point, model 2. (m) Front and $(\mathbf{n})$ side view in streamline inside the aneurysm at diastole time point, model 2. (o) WSS and (p) velocity distribution over the aneurysm surface at diastole, model 2. A color code is shown indicating the magnitude of WSS in units $\mathrm{Pa}$ and velocity in units $\mathrm{m} / \mathrm{s}$.

FIGURE 7. 2D wall shear stress analysis. (a) Centered aneurysms: i) Streamlines and shear stress profile for $H_{A} / W_{A}=1.75$ at $R e=400$ and $W_{N} / W_{P}=1$. ii) Aneurysm arc length ratio with low shear stress along aneurysm wall. (b) Offset aneurysms:

i) Streamlines and shear stress profile for $H_{A} / W_{A}=1.75$ at $R e=400$ and $W_{N} / W_{P}=1$. ii) Aneurysm arc length ratio with low shear stress along aneurysm wall.

FIGURE 8. Histogram of wall shear stress for 3D models. (a) Symmetric aneurysm WSS profiles: $H_{A} / W_{A}=1, W_{N} W_{P}=0.25, R e=300$ (black); $H_{A} W_{A}=1.5, W_{N} / W_{P}=1$, $R e=300$ (blue); $H_{A} W_{A}=1.75, W_{N} W_{P}=1.5, R e=300$ (red); $H_{A} W_{A}=1.5, W_{N} / W_{P}=1$, $R e=150$ (grey). (b) Sidewall aneurysm WSS profiles: $H_{A} / W_{A}=1, W_{N} W_{P}=0.25$, $R e=300$ (black); $H_{A} / W_{A}=1.5, W_{N} / W_{P}=1, R e=300$ (blue); $H_{A} / W_{A}=1.75, W_{N} / W_{P}=1.5$, $R e=300$ (red); $H_{A} W_{A}=1.5, W_{N} / W_{P}=1, R e=150$ (grey). (c) Pulsatile analysis showing model 1 at diastole (black) and systole (blue) and model 2 at diastole (red) and systole (grey).

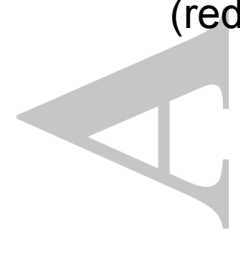


(a) (i)

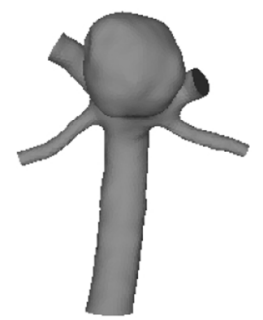

(b)

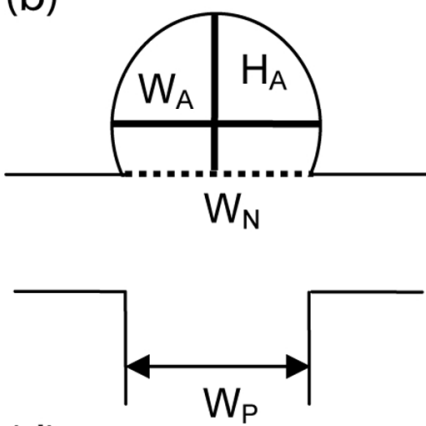

(d)

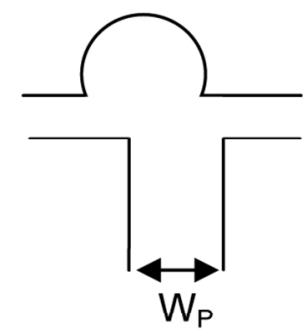

(f) (i)

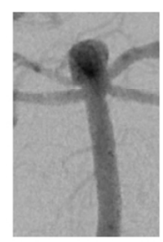

(ii)

(c)
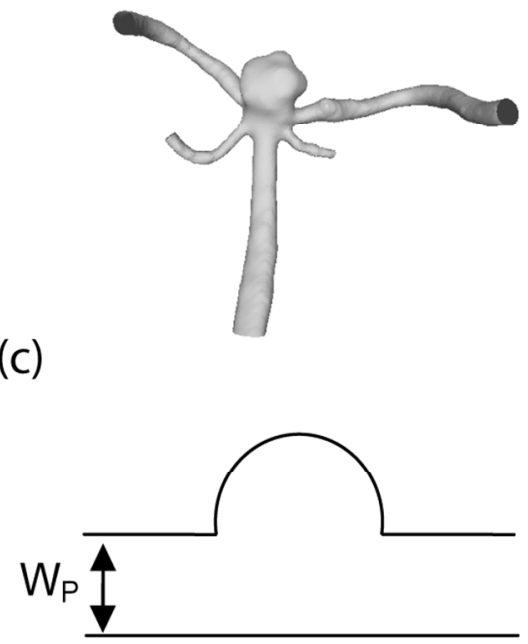

(e)

(ii)

Figure 1

$89 \times 136 \mathrm{~mm}(300 \times 300$ DPI $)$

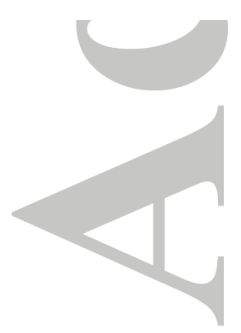

AIChE Journal

This article is protected by copyright. All rights reserved. 
(a) (i)

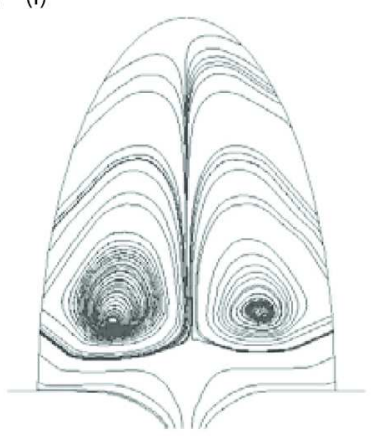

(b) (i)

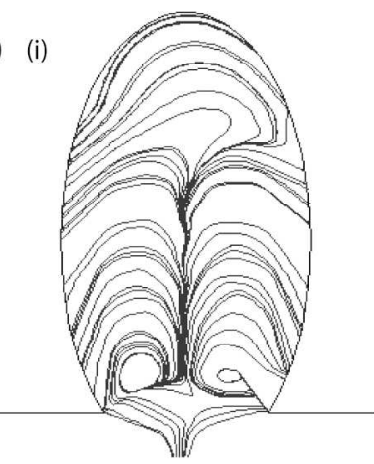

(c) (i)

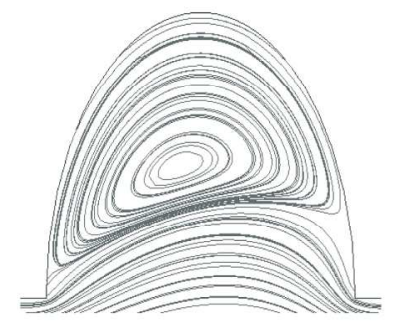

(ii)

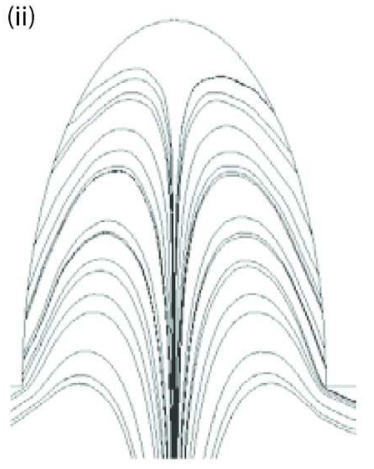

(ii)

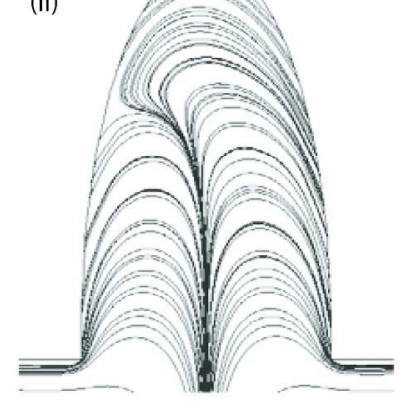

(ii)

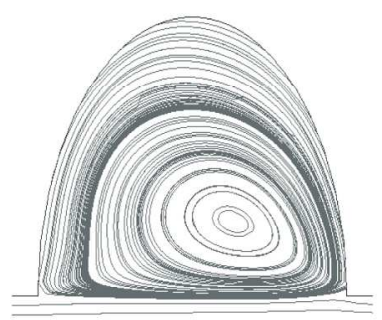

(iii)

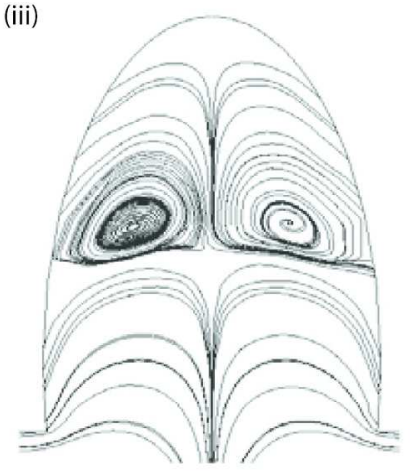

(iii)

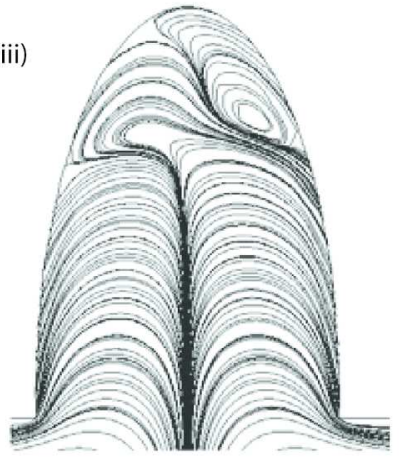

(iii)

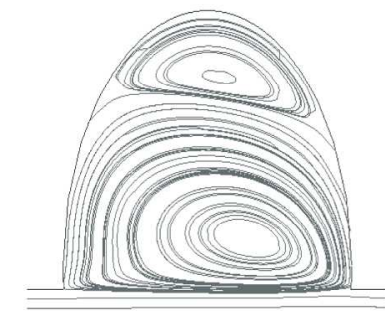

$177 \times 190 \mathrm{~mm}(300 \times 300 \mathrm{DPI})$

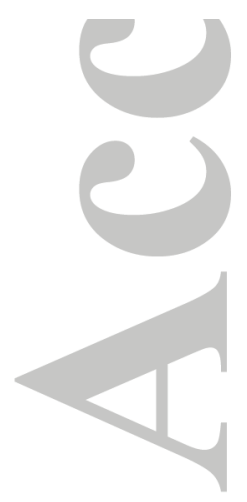

AIChE Journal

This article is protected by copyright. All rights reserved. 


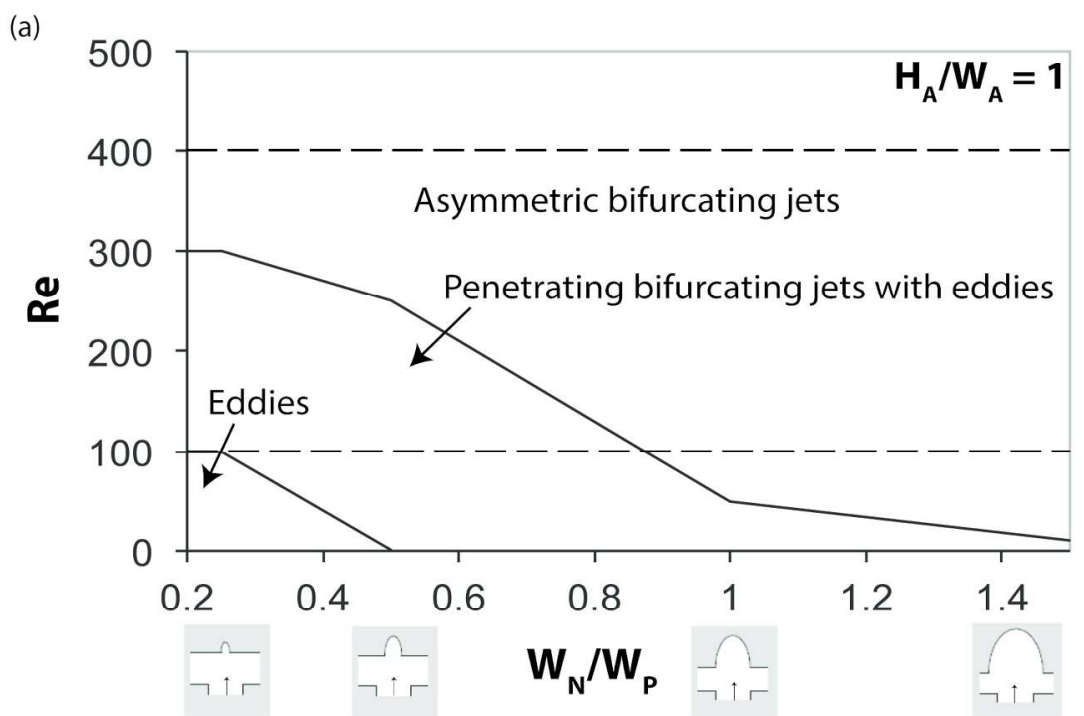

(b)

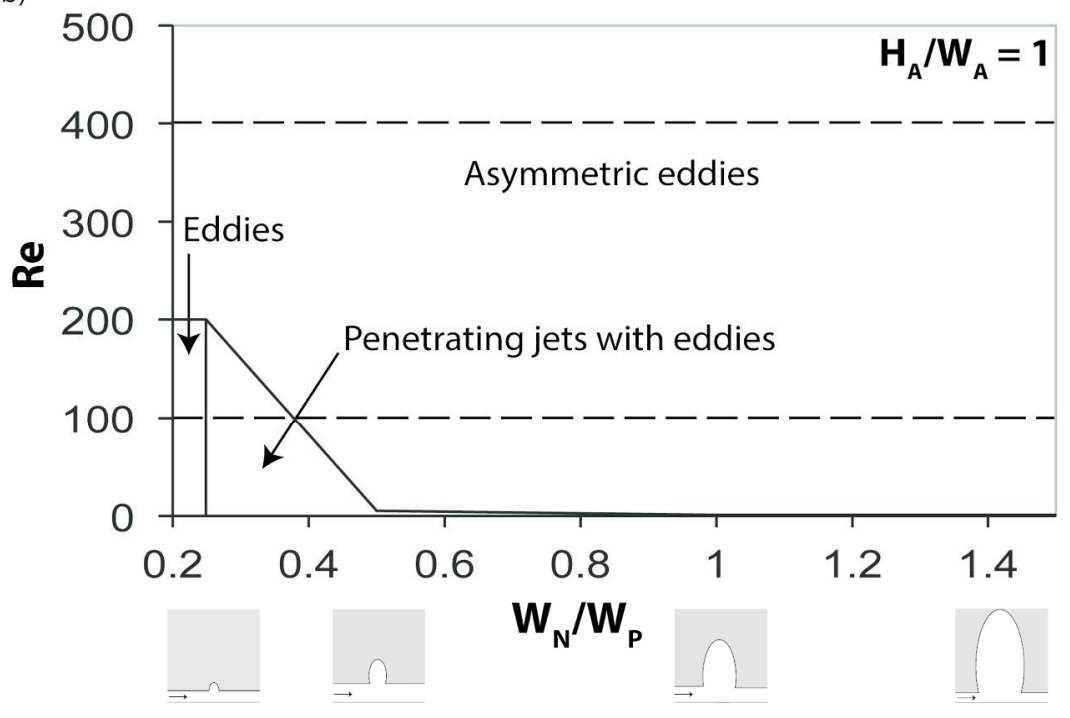

Figure 3

$156 \times 214 \mathrm{~mm}(300 \times 300$ DPI $)$

AIChE Journal

This article is protected by copyright. All rights reserved. 
(a)

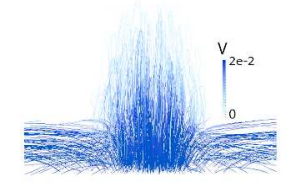

(e)

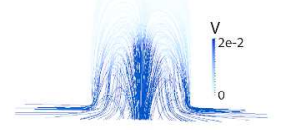

(i)
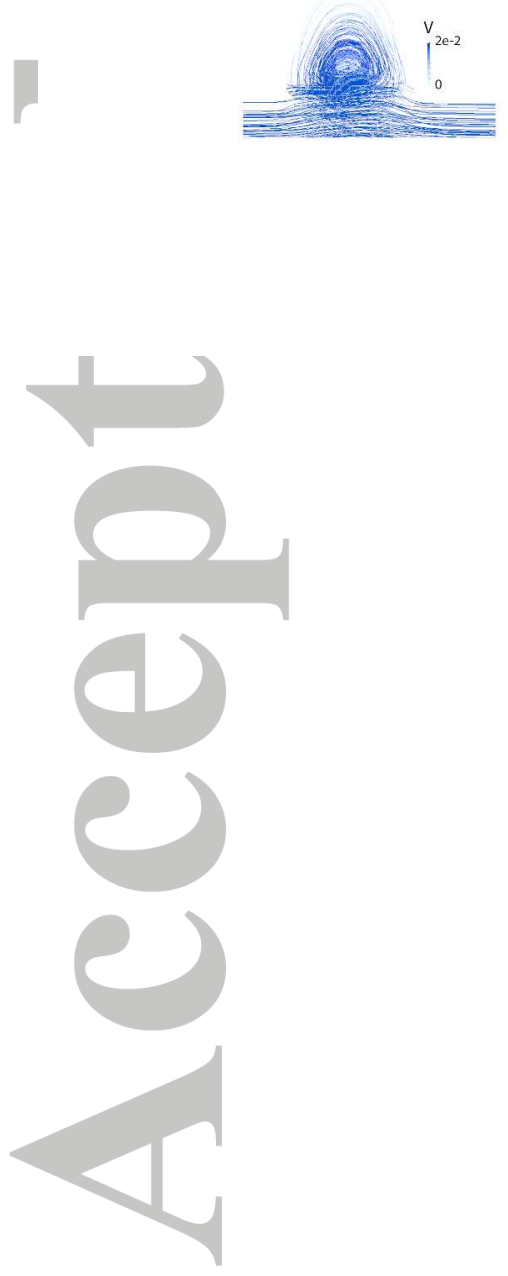

(b)

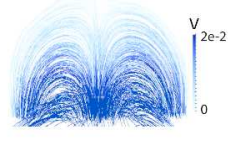

(f)

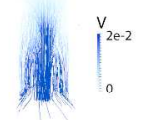

(j)

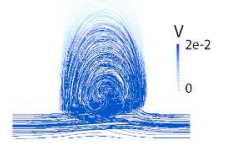

(c)

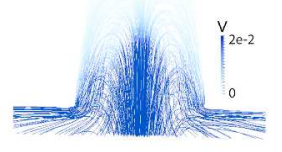

(g)

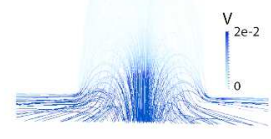

(k)

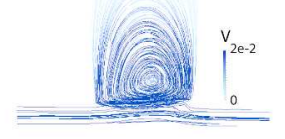

(d)

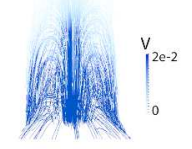

(h)

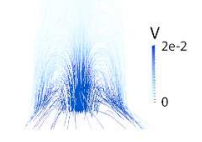

(I)

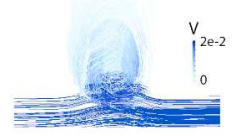

Figure 4

$262 \times 192 \mathrm{~mm}(300 \times 300 \mathrm{DPI})$

\author{
AIChE Journal
}

This article is protected by copyright. All rights reserved. 

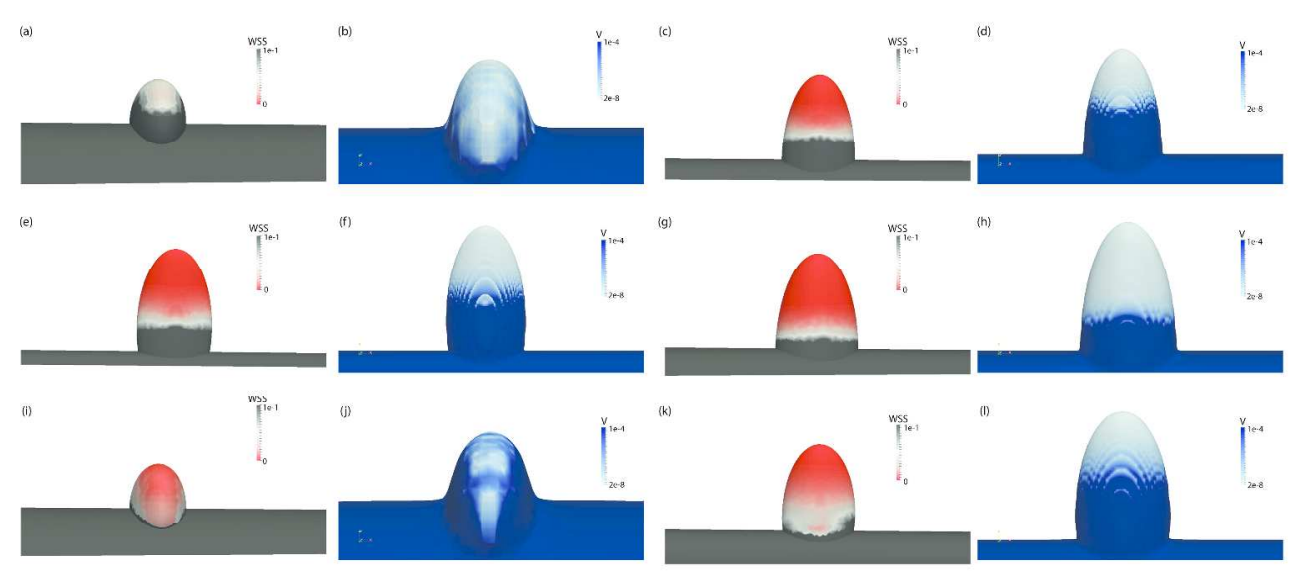

4
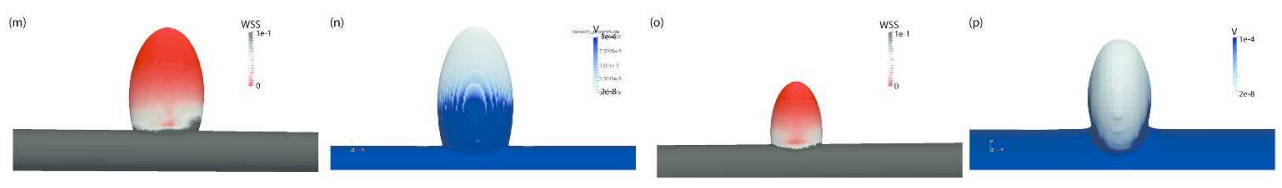

Figure 5

$433 \times 252 \mathrm{~mm}(300 \times 300 \mathrm{DPI})$

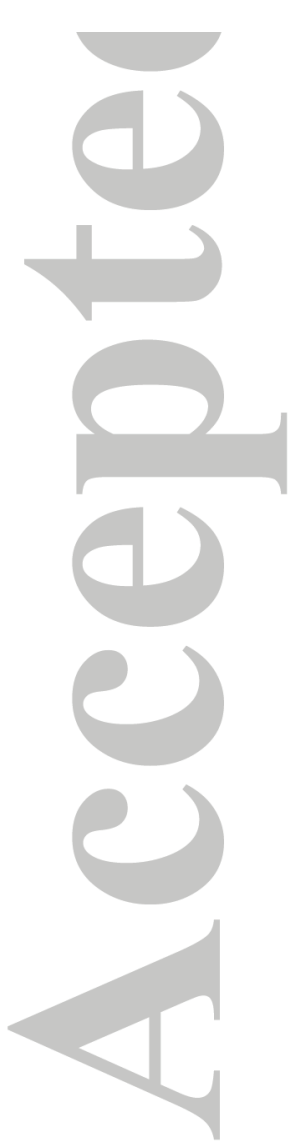

AIChE Journal

This article is protected by copyright. All rights reserved. 
(a)

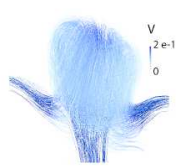

(e)

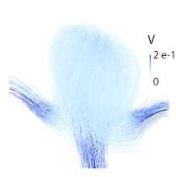

(i)

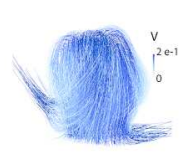

(m)

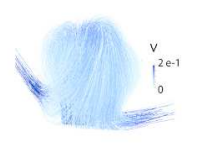

(b)

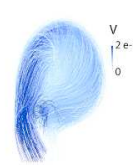

(f)

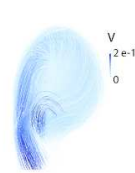

(j)

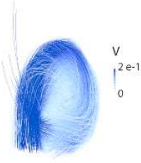

(n)

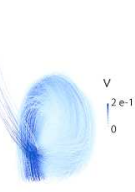

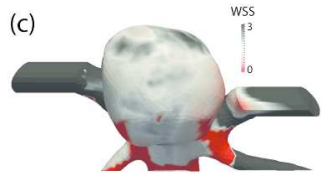

(g)

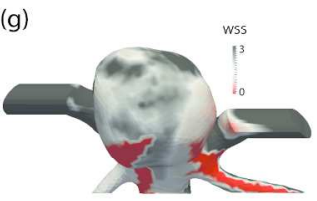

(k)

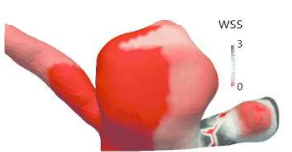

(o)

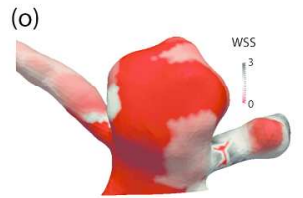

Figure 6 (d)

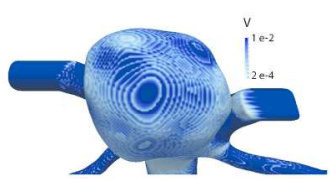

(h)

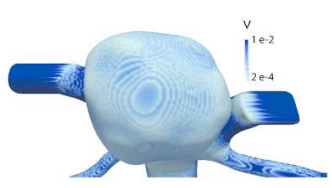

(I)

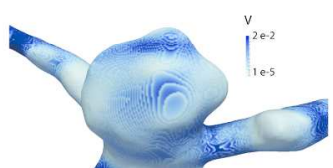

(p)

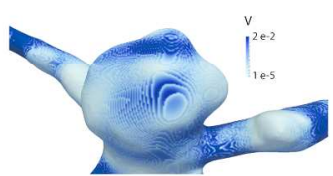

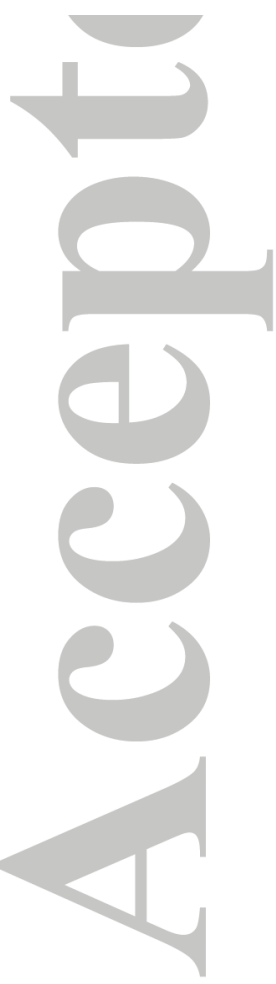

$207 \times 143 \mathrm{~mm}(300 \times 300$ DPI $)$

AIChE Journal

This article is protected by copyright. All rights reserved. 
(a) (i)

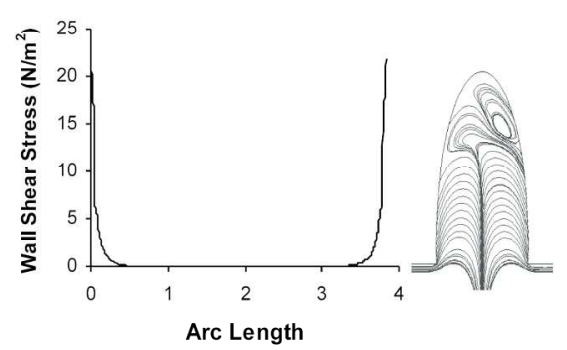

(b) (i)

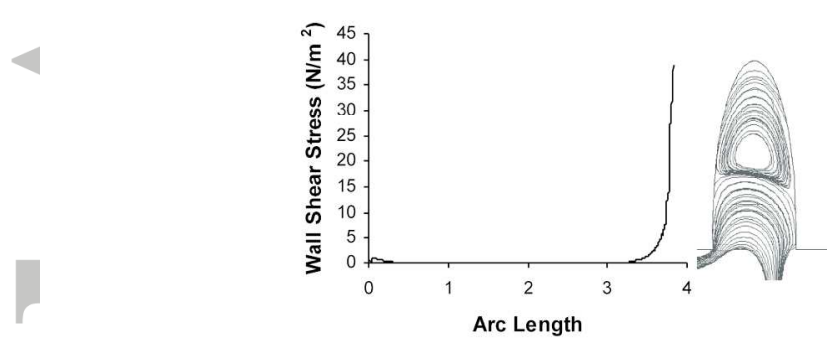

(ii)

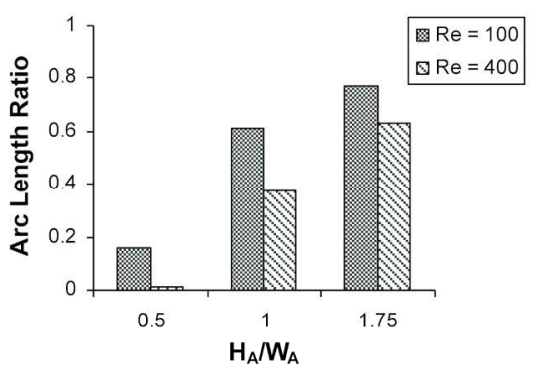

(ii)

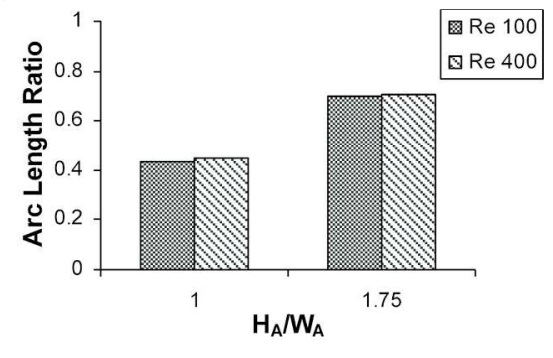

Figure 7

$188 \times 136 \mathrm{~mm}(300 \times 300$ DPI $)$

AIChE Journal

This article is protected by copyright. All rights reserved. 
(a)

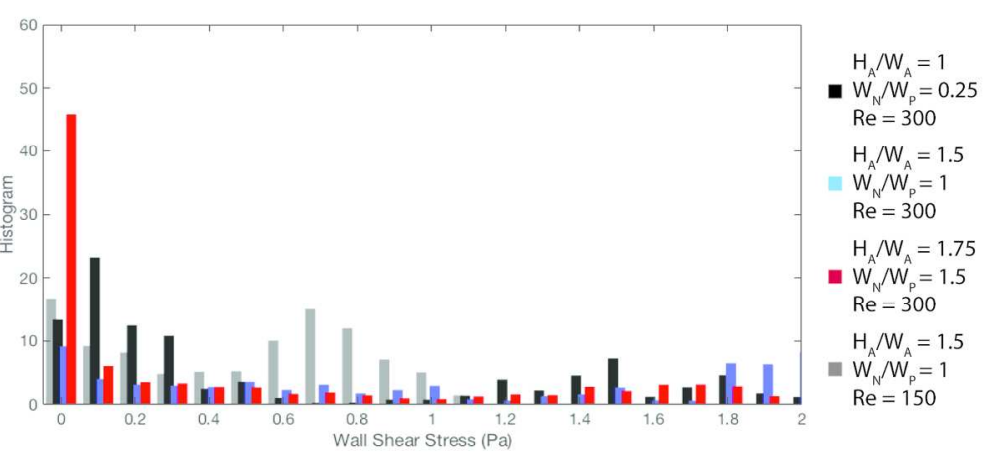

(b)

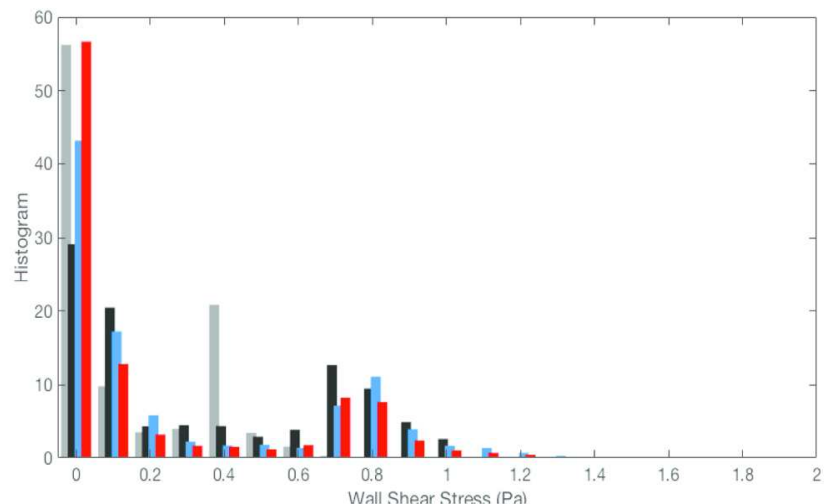

(c)

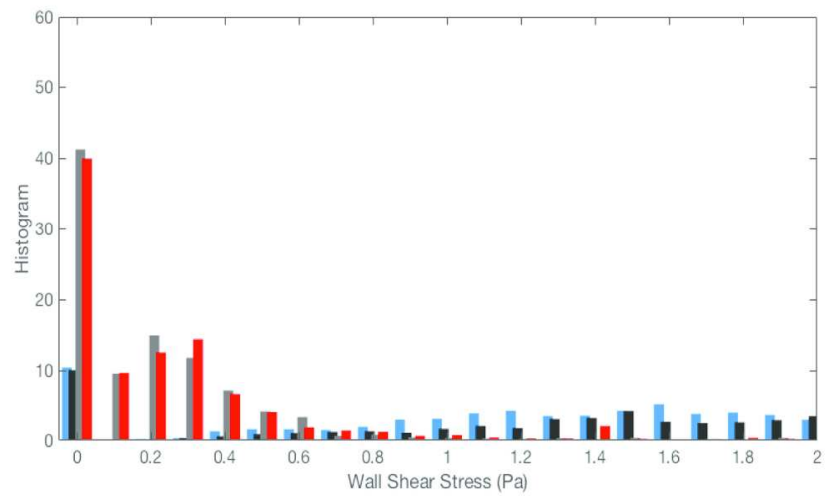

Figure 8

$151 \times 212 \mathrm{~mm}(300 \times 300 \mathrm{DPI})$

AIChE Journal

This article is protected by copyright. All rights reserved. 